\title{
Short-term memory in normal children and mental retardates'
}

NORMAN R. ELLIS AND MYRTIE MUNGER ${ }^{2}$

UNIVERSITY OF ALABAMA
Two studies are reported, using normal children and mental retardates, exploring a method (card guessing game) for studying short-term memory. Some methodological problems were investigated and procedural differences between previous studies were pointed out.

In a previous report Atkinson, Hansen, \& Bernbach (1964) have described a method for studying short-term memory in young children. The task, based on a children's card-guessing game, appears to hold the child's interest over the test period and to yield orderly data. It consists of exposing eight cards (animal pictures) one at a time; after exposure, the cards are placed face down forming a horizontal row before the child. A sample card identical to one of the eight is placed face up and the child is instructed to turn up the matching card. The procedure is arranged so that each of the eight positions is sampled equally often and the probability of a correct response for each position is assessed. Hansen (1965) in a follow-up study investigated exposure rate and Calfee, Hetherington, \& Waltzer (1966) studied the effects of number of cards.

Study 1 attempts systematic replication of the Atkinson et al study using a group of 5- and 6-yr.-old normal children and a group of mental retardates. Study 2 derives from Study 1 and is designed to assess several methodological variables.

\section{Study 1}

Ss were 20 mental retardates, CA 16 to $25 \mathrm{yr}$, mean 20 yr., and IQs 59 to 93 , mean 70 . The 28 normal Ss had CAs from 4 yr. 10 mo. to 5 yr. 11 mo., mean 5 yr. 10 mo. The test materials consisted of a set of 12 colored picture cards, 3-1/4 in. by 2 in. (a broom, spoon, flag, hat, hammer, key, monkey, ring, rabbit, wagon, cow, and church). As in the Atkinson et al study eight cards were randomly selected for each trial and exposed one at a time and placed face down in a horizontal row before $S$. A sample card was turned face up and $S$ was instructed to find the match. $S$ responded until a match was made. The procedure was arranged so that the eight positions were sampled equally. The retarded Ss were given 32 trials (about $1 \mathrm{hr}$ ), the normal children, 16 (15 to 20 min.). The latter were inattentive and sufficient interest could not be maintained over 32 trials.

\section{Results and Discussion}

Figure 1 depicts percent correct of first choice responses as a function of position (where 1 refers to the most recently shown card). Analysis showed that the first and last 16 trials for the retarded group yield essentially similar data. Therefore the last 16 trials of the retardates were not included in further analyses. There are obvious differences between our findings and those of Atkinson et al. Performance of the 5-yr. olds in the present study is inferior and shows both a primacy and a recency effect. Our retarded Ss perform at a higher level than the normals of lower mental age though the differences are not as large as might be expected on the basis of MA alone. The retarded S'S ( $\bar{X}=$ MA 9 yr. 10 mo.) performance falls far below that of the normal 5-yr. olds in the Atkinson et al study, indeed, even below that of their 4-yr. olds. In agreement with the finding of Atkinson et al, generalization is seen in these data. The mean of total errors made in each of the two adjacent positions when $2,3,4,5,6,7$, are correct was 8.17 , and that for nonadjacent positions was $4.80(t=2.31$, df $=54, p<.05)$ for the normal S. Similar analysis for the retarded Ss yielded means of 7.83 and 2.50 and $a t$ of $3.25(d f=54, p<.01)$. A further analysis compared the means of errors made in the positions "before" (more remote) with those made "after" (more recent) the correct positions 2, 3, 4, 5, 6 , and 7. For the retarded the "before" mean was 6.43 and that for "after" was 7.71. Those for normals were

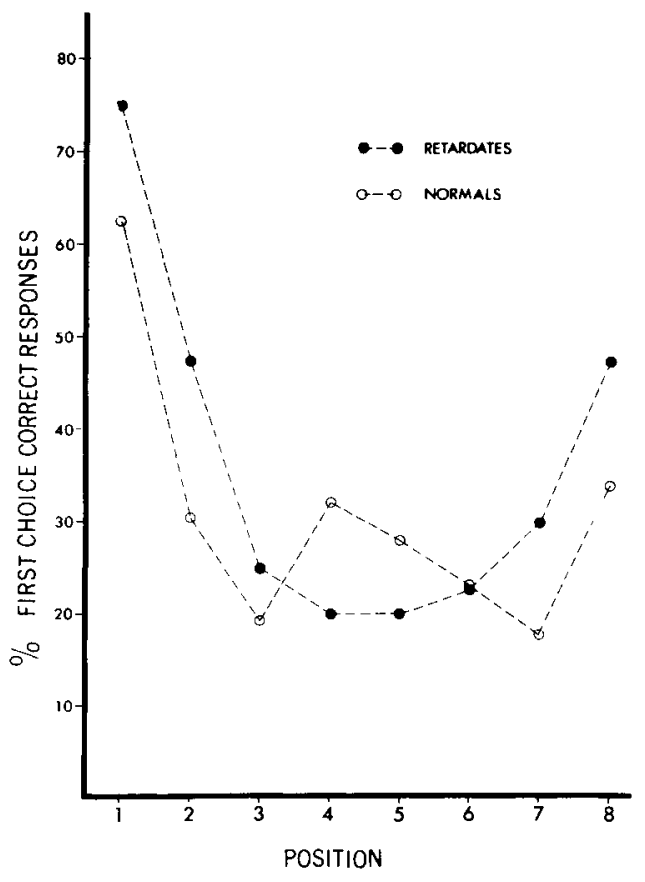

Fig. 1. \% first choice correct responses for the retardates and normal Ss at each position. 


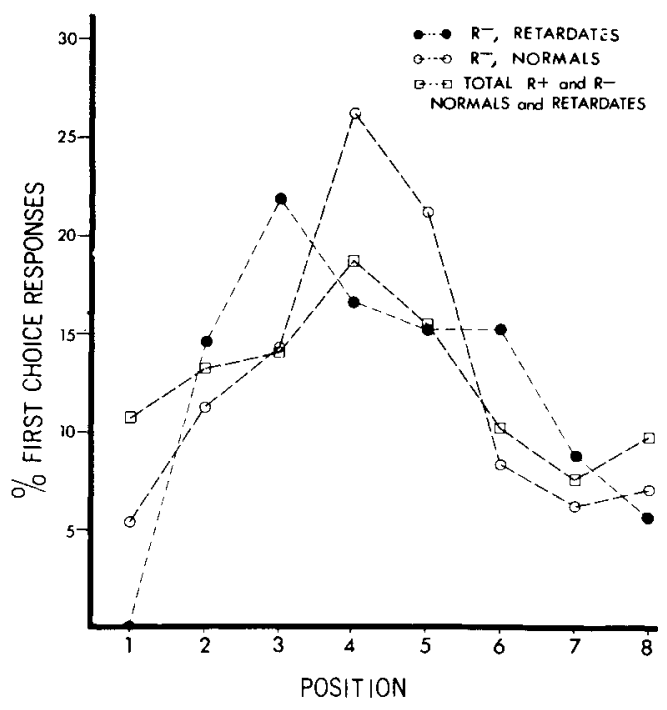

Fig. 2. \% first choice responses for each position including first choice errors for retardates and normals, and combined total correct and total errors for both groups.

6.29 and 8.57. Although these differences are not statistically significant they are in the expected direction. Atkinson et al found a marked tendency to respond in error to the more recent position.

A strong tendency to respond to a middle position is shown in Fig. 2, a finding also reported by Calfee et al. Moreover, Fig. 2 depicts a tendency to respond to a more recent position (correctly or in error). This tendency may reflect better memory of items in these positions. On the other hand, it should be noted that the cards are presented to $\mathrm{S}$ from his left to right, therefore recency and position are confounded.

Study 2

Study 2 attempted to assess the effects of presenting the cards in a left to right order. Since right side coin-

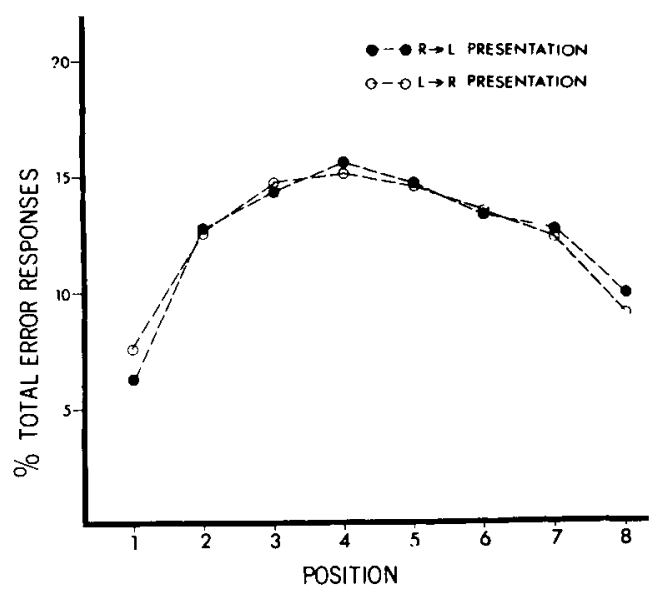

Fig. 3. \% total error responses for the two presentation orders. cides with recency this factor could have important methodological implications. Secondly, the Ss were required to name the picture on each card at the time of exposure. This procedure was expected to raise the overall performance level thus providing a more appropriate difficulty level for the retarded Ss.

Ss were 20 retardates, CA 15 to $26 \mathrm{yr}$., mean 22 yr.: IQs, 51 to 75 , mean 57.9 . Thirty-two trials were given, 16 displayed from $S^{\prime} s$ left to right and 16 trials in which the display order was reversed.

A plot of \% first choice correct responses for each position for the two display orders showed differences to be negligible with the exception of Position 8: this difference $\left(x^{2}=5.83, \mathrm{df}=1, \mathrm{p}<.05\right)$ suggests that memory of the most remote item is better when this item is presented on S's right, i.e., a right to left presentation order. Figure 3 presents total error responses for each position for the two display orders. A slight but insignificant tendency to respond to the right side may be noted. The strong tendency to respond to middle positions is clearly in evidence. It is likely that the procedure used in this study increased the difficulty of the task by "disturbing" positional cues.

In summary, our findings agree in general with previous studies using this methodology. Performance levels of our normal Ss are lower than comparable Ss in other studies. Both a recency and a primacy effect are found in the present study. Our studies and those of others suggest that several variables may appreciably influence performance on this task including ability and/or developmental level, item presentation rate, number of items in task, whether or not the picture is named when exposed, whether one or eight sample cards are used, and presentation order. The last effect seems mainly confined to the memory of the first item presented. There appears to be a tendency to respond to middle items, to the right side, to error by responding to cards presented more recently than the correct one, and to make generalization responses, i.e., to respond to positions near the correct one.

\section{References}

Atkinson, R. C., Hansen, D. N., \& Bembach, H. A. Short-term memory with young children. Psychon. Sci., 1964, 1, 255-256.

Calfee, R. C., Hetherington, E. Mavis, and Waltzer, Phyllis. Shortterm memory in children as a function of display size. Psychon. Sci., 1966, 4, 153-154.

Hansen, D. N. Short-term memory and presentation rates with young children. Psychon. Sci., 1965, 3, 253-254.

\section{Notes}

1. This research was supported by a grant from the National Institute of Mental Health, Public Health Service, grant No. MH 10724. 2. We wish to express appreciation to the following for their cooperation in the conduct of these studies: Dr. Joseph E. Barrett, Asst. Supt., Mr. James Price and Mrs. Marilyn Methvin, Staff Psychol., and to Mrs. Mildred McLendon, Dir. Nursing, all of Partlow State School; Mrs. Malcolm G. Edwards, Dir. and Mrs. Gene Williams, Asst. Covenant Presb. Church Nursery-Kindergarten. 